BMJ Open

Sport \&

Exercise

Medicine

\title{
Coaches' attitudes to injury and injury prevention: a qualitative study of Irish field hockey coaches
}

\author{
Huw Rees (1) , ${ }^{1,2}$ James Matthews, ${ }^{1,2}$ Ulrik McCarthy Persson, , \\ Eamonn Delahunt, ${ }^{1,2}$ Colin Boreham, ${ }^{1,2}$ Catherine Blake ${ }^{1,2}$
}

\begin{abstract}
To cite: Rees H, Matthews J, McCarthy Persson U, et al. Coaches' attitudes to injury and injury prevention: a qualitative study of Irish field hockey coaches. BMJ Open Sport \& Exercise Medicine 2021;7:e001074. doi:10.1136/ bmjsem-2021-001074

- Additional supplemental material is published online only. To view, please visit the journal online (http://dx.doi. org/10.1136/bmjsem-2021 001074).
\end{abstract}

Accepted 21 July 2021

\begin{abstract}
Translating injury prevention research into practice has been challenging, which may be due to a poor understanding of the contextual factors influencing the occurrence of injury. Coaches are key figure in sporting environments and hold pivotal roles in preventing injury. Therefore, the aim of this study was to investigate the attitudes of field hockey coaches to injury and injury prevention. Thirteen field hockey coaches from the amateur Irish Hockey League were interviewed. Reflexive thematic analysis led to three general dimensions comprised five higher-order themes, categorised from 16 lower-order themes. Coaches had positive beliefs regarding the benefits of injury prevention over injury management. However, they lacked the necessary knowledge and skills to successfully implement injury prevention strategies with players. Coaches recognised the importance of empowering players to self-manage training loads to promote injury prevention but acknowledged the need to protect younger players from increased loads. Many barriers to injury prevention were not controllable by coaches including fixture congestion and poor structuring of the sport's domestic calendar. While coaches can play a key role in the implementation of injury prevention strategies, there is also a requirement to examine how system level barriers to injury prevention can be reduced.
\end{abstract}

\section{INTRODUCTION}

Check for updates

\section{(c) Author(s) (or their} employer(s)) 2021. Re-use permitted under CC BY-NC. No commercial re-use. See rights and permissions. Published by BMJ.

${ }^{1}$ School of Public Health, Physiotherapy and Sport Science, University College Dublin, Dublin, Ireland ${ }^{2}$ Institute for Sport and Health, University College Dublin, Dublin, Ireland

Correspondence to Dr Huw Rees; huw.rees94@gmail.com
Field hockey is a physically demanding sport, ${ }^{1}$ with injury surveillance studies to date reporting injury incidence rates between 7.8 and 11.8/1000 hours. ${ }^{2-4}$ Little research has been undertaken in an attempt to reduce the number of injuries incurred in the sport. This is particularly evident through the lack of implementation of, and compliance with injury prevention programmes within squads. ${ }^{5}$ It has been suggested that factors such as the knowledge and attitudes of coaches towards injury prevention may have a role in the non-compliance of athletes to such injury prevention programmes. ${ }^{6}$ There is a vital need to explore the role of the coach in the implementation of, and compliance with injury prevention initiatives. ${ }^{7}$

\section{Key messages}

What is already known?

- Injury prevention research is lacking in field hockey, with most research solely investigating quantitative count data related to injury epidemiology.

- To date, no studies have investigated contextual factors that may impact the rate of injury and injury prevention in field hockey.

- Traditionally, injury prevention in sports has been underpinned by the sequence of prevention, a fourstage linear framework involving only quantitative methods.

What are the new findings?

- Field hockey coaches are generally open to the idea of implementing injury prevention strategies within their squads.

- Coaches lack the specialist skills and underlying knowledge to prevent injuries.

- Many factors which may affect the rates of injury incurred in field hockey, such as the domestic calendar, are out of the coaches' control.

- Qualitative studies are needed in order to investigate the underlying attitudes of relevant stakeholders and contextual factors related to sporting injury.

Traditionally, injury prevention in sports has been underpinned by the sequence of prevention, a four-stage framework involving only quantitative methods. ${ }^{8}$ While useful, this particular framework does not consider the non-linear and complex nature of sporting injury. ${ }^{9}$ Indeed, researchers have suggested that until alternative factors, such as the attitudes and behaviours of key stakeholders are better understood, the implementation of injury prevention programmes is likely to be difficult, and ultimately unsuccessful. ${ }^{10}$ In fact, an alternative model, which was developed based on the sequence of prevention, has highlighted the need to conduct qualitative research to better understand the role of relevant stakeholders. ${ }^{11}$ However, despite this call to action, only a small number of studies examining coaches' perspectives have been undertaken. $^{12-14}$ 
Adopting qualitative methods to determine coaches' attitudes towards injury and injury prevention can provide richer insights into these contextual factors pertaining to injury, and ultimately may assist practitioners and researchers in targeting these factors to support the effective implementation of injury prevention programmes. For this reason, the purpose of this study was to explore coaches' attitudes to injury and injury prevention in field hockey.

\section{MATERIALS AND METHODS}

\section{Patient and public involvement}

Participants in this study first became involved prior to the commencement of the interview process. A questionnaire was developed to gain an initial understanding of the participants' attitudes towards injury prevention, and responses to this questionnaire were used to formulate the interview guide. These responses also identified areas for further exploration, thus assisting in the development of the research questions. All head coaches were known to the first author, allowing ease in recruitment. However, head coaches assisted in the recruitment of the teams' assistant coaches by explaining the process and necessity of the research. Following the completion of the interview process, all transcripts were returned to the participants to review, and to finalise the data that would go for analysis.

\section{Study design and context}

The data collection and analysis process followed the Consolidated criteria for Reporting Qualitative research guidelines. ${ }^{15}$ This study adopted interpretivism as its philosophical position, assuming that there is no single external reality independent of the individual, rather reality exists in the form of multiple mental constructs. ${ }^{16}$ The study was situated within the Irish Hockey League (IHL). This league is the highest level of hockey in Ireland, with teams from this league competing at European level and clubs typically containing players who represent the national team. However, players are amateur and coaches will generally have careers away from the sport. Some coaches will be compensated for their coaching responsibilities, while others will perform their responsibilities on a voluntary basis. In addition, some clubs will have resources available to players, such as a physiotherapist or a club gym, while others will not.

\section{Participants and procedures}

Participants were recruited from the IHL. Initially, head coach participants were recruited using purposive sampling. Thereafter, snowball sampling was used in an attempt to recruit the teams' assistant coaches. ${ }^{17}$ In total, 10 head coaches were approached via email, of whom seven agreed to participate in the study. Following discussion with the relevant head coaches, eight assistant coaches were identified and approached via email, of whom six agreed to an interview. We used semi-structured interviews to explore the attitudes of these coaches towards injury and injury prevention in sport. Prior to being interviewed, informed consent and preliminary data were collected from the coaches using a short questionnaire, including demographic information such as age, coaching qualification and coaching experience, as well as their initial beliefs regarding risk factors to injury (eg, age, previous injury, etc), and initial attitudes towards injury prevention (eg, specific strengthening proprioception training, etc). The responses to this questionnaire were used to inform the development of the interview guide. The interview guide consisted of five sections: section one focused on some introductory questions; section two on communication within the squad; section three on their attitudes towards injury; section four on their attitudes towards injury prevention and section five asked for their response to three contextually driven scenarios (see online supplemental file 2). All 13 participants were men, aged between 34 and 60 . Coaches had playing experience ranging from 16 to 30 years, with five having played field hockey at an international level. Coaching experience ranged from 3 to 25 years, with seven having coached at international level, and four of those at senior international level. Five interviews took place face-to-face, with the remaining eight being conducted via Skype. Interviews were conducted by the first author, who had a background of participating in field hockey as a player, as well as being employed by clubs in the IHL as a physiotherapist. While a minimum of six interviews has been suggested for thematic analysis, there are no strict guidelines for data saturation. ${ }^{18}$ A focus on the meaning taken from the sample rather than the size of the sample itself is encouraged. ${ }^{19}$ After 11 interviews, the interviewer noticed there were no new themes emerging that would add to the data. Two final interviews were done to confirm this, and the data collection process then ceased.

\section{Data analysis}

Interviews ranged from 32 to $65 \mathrm{~min}$ in duration (mean=45:55, SD=10:30) and were transcribed verbatim. Data were analysed through the NVivo software ${ }^{20}$ using Braun and Clark's principles of reflexive thematic analysis. ${ }^{21}$ First, the lead author familiarised himself with the data through reading and re-reading the transcripts. Following this, the transcripts were coded by generating succinct labels that identified important features within the dataset. Once the data had been coded, they were examined and collated in an attempt to identify broader patterns of meaning. The data were then collated for potential themes, which were reviewed against the dataset to determine whether or not they told a convincing story which addressed the research question. Once the themes were finalised and appropriate data collated for each, the themes were defined and named. The data were then written up into results, by weaving the themes together, with data extracts. ${ }^{22}$ To ensure the rigour and trustworthiness of the data, criteria were drawn from the work of Trace $^{23}$ and included worthy topic, rich rigour, credibility 
and sincerity. Coaches' attitudes towards injury and their role in injury prevention were deemed an important topic due to the increasing focus on player well-being in sport. Rich rigour was achieved by interviewing experienced coaches who gave in-depth accounts. Credibility was addressed by member reflections and peer triangulation. ${ }^{24}$ The coach participants were sent the interview transcripts and were asked to share any further insight that might have been prompted from reviewing the transcript. Furthermore, members of the research team interacted with the lead author and considered different interpretations of the data with the aim of developing a fuller understanding through this dialogue. Finally, sincerity was achieved by the lead author keeping a reflexive diary to reflect on different interpretations of the data through the analysis process.

\section{RESULTS}

Five higher-order themes with 16 related lower-order themes were categorised under three general dimensions. The first general dimension examined the attitudes of coaches to injury prevention and incorporated two higher-order themes: coaches value injury prevention and identification of risk factors; and player safety and welfare are the priority. The second general dimension explored the coaches' impact on injury prevention and consists of the higher-order themes: style of coaching and communication attempt to ensure player safety; and injury prevention needs to be age-specific. The final general dimension focused on the contextual barriers to injury prevention and discusses the final higher-order theme: environmental and system-level barriers to injury prevention. Figure 1 highlights the interaction between lower-order themes, higher-order themes and general dimensions. Furthermore, the tables provide key quotes from the coaches which accompany each of the presented general dimensions. To allow the authors to blend the coaches' perspectives to build a reality based on multiple constructs, results were interpreted by the authors and collated. This was in keeping with the philosophical paradigm for this study.

\section{Attitudes of coaches to injury prevention}

Quotes to illustrate each of the themes associated with coaches' attitudes to injury prevention are presented in table 1 . The majority of coaches were positive about injury prevention. This was evident through coaches being open to allowing periods of rest for their players, the value they placed in 'trying for prevention rather than treatment ... by managing players' and their emphasis on player safety. Coaches expressed the importance of being able to identify the risk factors related to injury to inform prevention. To do this, coaches tended to rely on commonly accepted risk factors to injury in sport such as the workload placed on athletes in matches and training, a lack of recovery postgame or athletes being 'too light and not strong enough'. While the degree to which clubs implemented injury prevention strategies varied significantly from team to team, coaches often relied on their own limited knowledge, employing some commonly used prevention strategies. For example, a progressive 'running
Lower-Order Themes

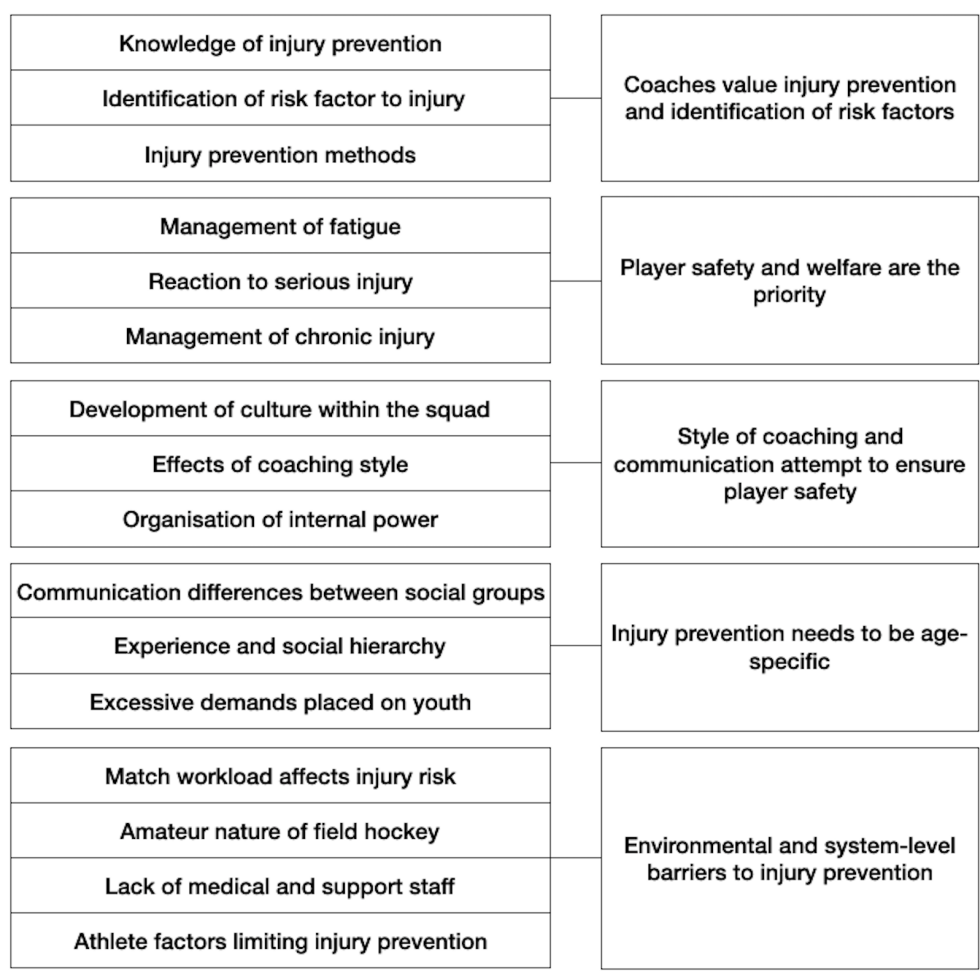

General Dimensions

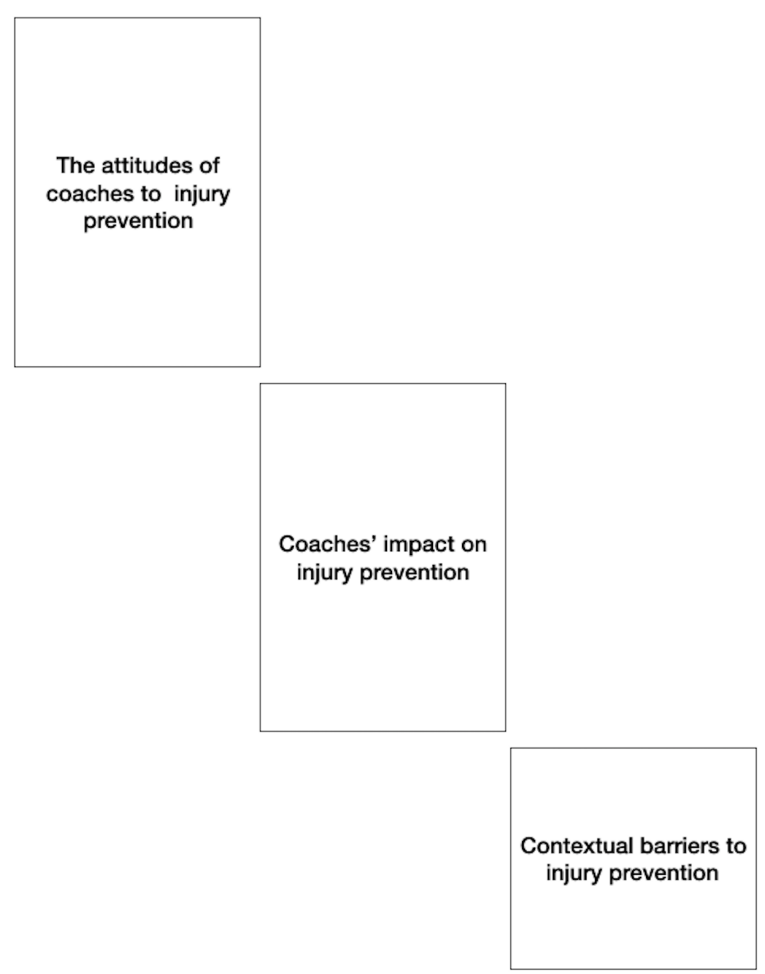

Figure 1 The development of the general dimensions, higher-order themes and lower-order themes through reflexive thematic analysis. ${ }^{21}$ 
Table 1 Main codes and related quotes on the dimension 'the attitudes of coaches to injury prevention'

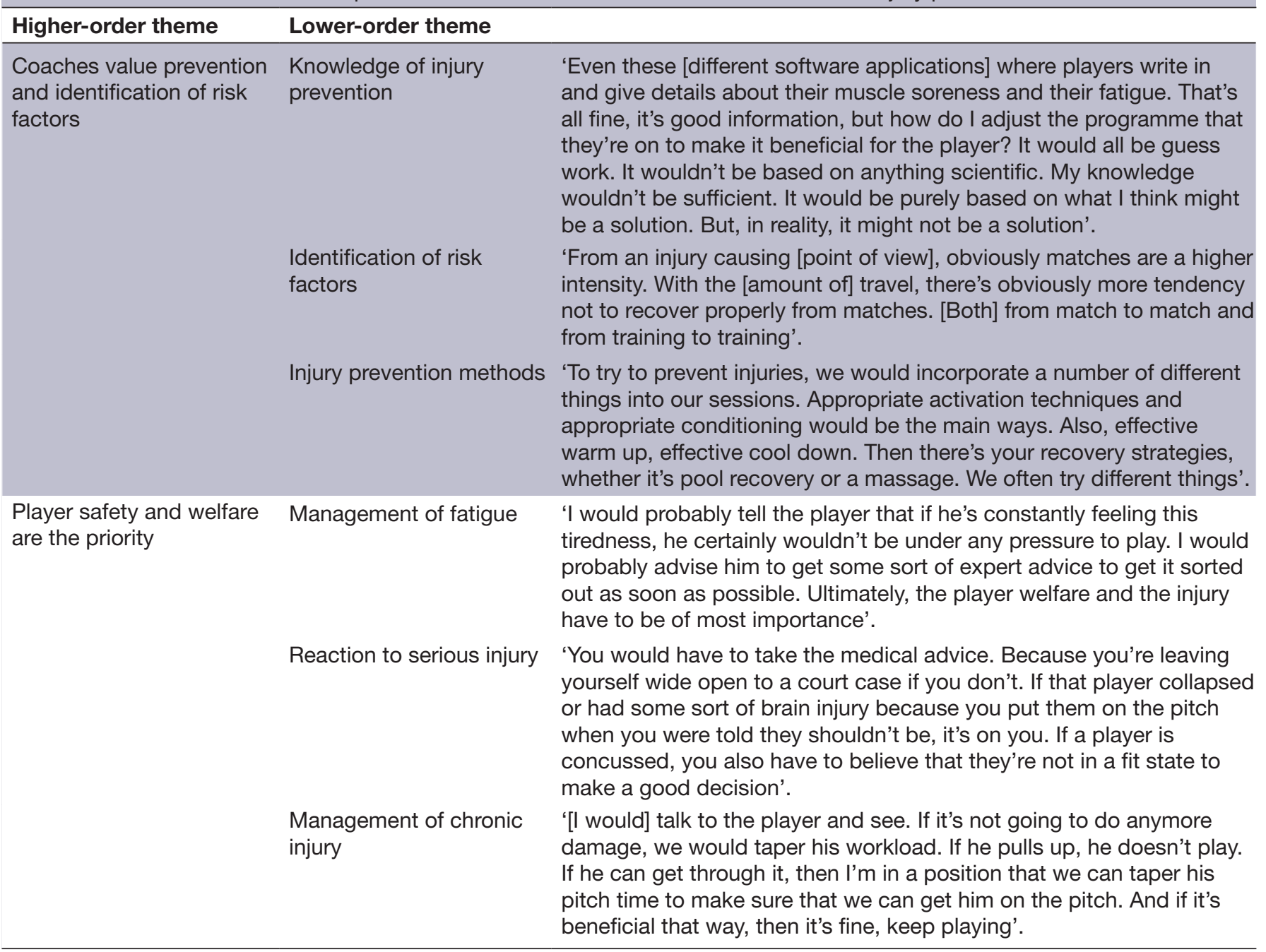

programme where players build up [to match intensity]' and modifying load by 'lengthening the video analysis period, lengthening the warmup and cool down periods' were used. However, coaches indicated that they did not have sufficient knowledge to comprehensively manage injury prevention (see table 1 , lower-order theme 1) and 'screening would be enormously beneficial' to highlight areas of increased risk or weakness for players. This level of specialist support was often not feasible because 'it's a costly thing to do'. This typically left coaches holding all of the responsibility for injury prevention.

\section{Coaches' impact on injury prevention}

Table 2 provides data-rich quotes for each of the lowerorder themes associated with the dimension examining coaches' impact on injury prevention. Coaches influenced injury prevention through the manner in which they interacted with their players, with 12 of the 13 coaches attempting to empower players to make their own decisions regarding training workload (see table 2, lower-order theme 2). One coach, however, took a notably less inclusive approach to coaching, stating that he is 'the decision maker and [the players] follow [his] lead'. Coaches did not exhibit signs of a win-at-all-costs mentality, placing the welfare of the player above all else. Interestingly, coaches' promotion of player autonomy was moderated by the age of the players. Coaching staff were more open to senior players contributing to the management of workload than they would be with younger athletes. This was evident in one coach noting that 'this week [the senior players] came to [him] and said maybe we should go a bit lighter on Tuesday', because they had a particularly demanding match on the weekend. On the other hand, they highlighted the need to take a more hands-on approach with younger athletes as they need more assistance with elements such as recovery and managing workload. Furthermore, younger players were also viewed as being particularly vulnerable (see table 2, lower-order theme 6). Playing for multiple teams across a season at school, club and international level has seen the demands and pressure on school-aged athletes increase significantly. This was illustrated by one coach identifying a school-aged player "who is a senior international and played 93 games in a year'. All IHL coaches reported having to monitor and manage the training load of 
Table 2 Main codes and related quotes on the dimension 'coaches' impact on injury prevention'

\begin{tabular}{|c|c|c|}
\hline Higher-order theme & Lower-order theme & \\
\hline \multirow[t]{3}{*}{$\begin{array}{l}\text { Style of coaching } \\
\text { and communication } \\
\text { attempt to ensure } \\
\text { player safety }\end{array}$} & Development of culture & $\begin{array}{l}\text { 'This year, we've tried to make it more open. "Right, this is what we think, } \\
\text { what do the players think?" We're trying to make it more open, a bit more } \\
\text { transparent. It's not such a closed shop anymore. It's not just what the } \\
\text { coach says, goes. It's trying to get everybody better at making decisions, } \\
\text { particular when managing load'. }\end{array}$ \\
\hline & Effects of coaching style & $\begin{array}{l}\text { 'It's important to listen to the player. Even if somebody is struggling, there's } \\
\text { things you can do. You don't have to not train. You can still do things at } \\
60 \% \text {, you can work on skills, you can do some shooting. You don't have } \\
\text { to be sprinting and fatiguing and so, I think listening to the player among } \\
\text { other [things] can minimise injuries'. }\end{array}$ \\
\hline & $\begin{array}{l}\text { Organisation of internal } \\
\text { power }\end{array}$ & $\begin{array}{l}\text { 'As I say to them all the time, [some of the players] have more experience } \\
\text { than we do. One of them has played in one of the biggest clubs in the } \\
\text { world and had been to an Olympics and a World Cup. So, why not try and } \\
\text { take some of his knowledge out'. }\end{array}$ \\
\hline \multirow[t]{3}{*}{$\begin{array}{l}\text { Injury prevention } \\
\text { needs to be age- } \\
\text { specific }\end{array}$} & $\begin{array}{l}\text { Communication difference } \\
\text { between social groups }\end{array}$ & $\begin{array}{l}\text { 'With some of the younger guys, there's certain things you don't want to } \\
\text { be doing with them. It's probably more of an arm around them and here's } \\
\text { what we should do. We're trying to just explain more to the younger guys } \\
\text { as much as to why we're doing things. Obviously still valuing their opinion, } \\
\text { but they tend not to say much'. }\end{array}$ \\
\hline & $\begin{array}{l}\text { Experience and social } \\
\text { hierarchy }\end{array}$ & $\begin{array}{l}\text { 'The elite athletes and [senior players] will demand more information. "Ok, } \\
\text { I'm injured, what am I supposed to do about it?" They drive the standards. } \\
\text { The coach or the manager can put out an aspirational standard, but it's } \\
\text { actually the players that drive it'. }\end{array}$ \\
\hline & $\begin{array}{l}\text { Excessive demands } \\
\text { placed on youth }\end{array}$ & $\begin{array}{l}\text { 'If you're working with younger players, a lot of them aren't going to have } \\
\text { the necessary experience and knowledge to know when enough is enough } \\
\text { or how far can push themselves and would tend to over push themselves. } \\
\text { At this stage, it's the responsibility of the coach and [senior players] to } \\
\text { give them the information and to recognise when players have pushed } \\
\text { themselves too far or potentially could'. }\end{array}$ \\
\hline
\end{tabular}

these younger athletes, reporting that '[school coaches] are not interested in what [young athletes] do further down the line for the club, or Irish 16's, 18's or 21's'. This extreme pressure placed on youth is particularly prevalent at certain points in the season, such as 'the all-Ireland school [tournament], played across threedays, where if you win it, you end up playing five matches'. Young athletes 'aren't going to have the necessary experience or knowledge' to understand that this level of workload is excessive and so, 'it's the responsibility of the coach and [senior] players to give this information'.

\section{Contextual barriers to injury prevention}

Finally quotes to highlight the lower-order themes regarding contextual barriers to injury prevention are presented in table 3. Field hockey is an amateur sport, with athletes playing as a community-based sport for exercise. Although the top level in Ireland, its amateur nature was considered a challenge with regards to ensuring athletes were match-fit and ready for selection as 'they're not professional athletes so there's always someone missing [from training]'. One of the most important factors associated with this is the athlete's access to medical resources within the club. Many clubs rely on one of their players undertaking a dual role, whereby the athlete happens to be a doctor of physiotherapist, often only being used 'on an emergency basis, for example if somebody got cut on the side of the pitch'. This was common across clubs, and made it challenging for coaches, particularly during matches, to determine whether or not an athlete can continue to play. However, coaches have come to terms with such an arrangement (see table 3, lower-order theme 3). Coaches were aware of the benefits of using software or data systems to integrate physical load monitoring, physical performance tests and self-report well-being, such as Kitman labs. However, they admitted lacking the skillset and knowledge required to 'adjust the programme that they're based on [that information], to make it beneficial to the player'. Furthermore, lack of awareness and knowledge of the benefits of injury prevention, including warmup methods, and the subsequent lack of buy-in from athletes, left coaches frustrated and often helpless (see table 3, lower-order theme 4). The introduction of the IHL as a season long competition has made the league more physically demanding for athletes, according to the majority of coaches. Double weekends, and a winter break which caused significant fixture congestion in the latter stages of the season were particularly to blame for this. Furthermore, the indoor hockey season, which runs parallel to the field hockey season for a period, means that 'from November onwards, some of the players could 
Table 3 Main codes and related quotes on the dimension 'contextual barriers to injury prevention'

\section{Higher-order theme Lower-order theme}

Environmental and Match workload affects system-level barriers injury risk to injury prevention

Amateur nature of field hockey

Lack of medical and support staff

Athlete factors limit prevention
'[Modifying training intensity is] definitely something you learn over time. We would speak to some of the guys playing abroad [in professional leagues] where they could have two or three sessions a day between strength and conditioning, outfield sessions and video sessions. It wouldn't be unheard of, especially around [times when we have a lot of matches], just to be running sessions for 1.5 hours'.

'It's purely voluntary from [a professionalism] point of view. But everyone is expected to play, to train on either the Wednesday or Thursday. But sometimes if a player has got an exam the next day or is away on business or can't make training for whatever reason, then we just have to accept that that's reality and get on with it really'.

'[Having access to medical resources] would be great if you had the time and the finances. I think both of them are a big factor. Finance obviously an issue, but it's the time factor as well. You're so limited. You have two hours with somebody. You've got to warm-up for half an hour. I don't know when we'd fit in being able to see a [club] physio'.

'[Our players] aren't focused on their cool down, they don't understand the importance of the cool down and other recovery [techniques]. Their warmup, their rehab on a Monday or Wednesday night or whatever they're doing. I just think we lack a bit of understanding'.-In relation to coaches general understanding of how it may be possible to prevent injuries. have two indoor training sessions a week, two outdoor training sessions a week, and matches as well'.

\section{DISCUSSION}

The primary aim of this study was to identify the attitudes of field hockey coaches towards injury prevention. We identified five higher-order themes which were examined under three general dimensions. The first of these dimensions, the attitudes of coaches to injury prevention, discussed the idea that field hockey coaches are in tune with the idea of injury prevention, at least as a general concept. However, they often struggle to implement such strategies due to their lack of skills and underlying knowledge. The second dimension, coaches' impact on injury prevention, highlights the role that coaches currently play in preventing injury among members of the playing squad. Finally, our third dimension, contextual barriers to injury prevention, examined the belief that many of the contributing factors to injury are out of the control of the coach and lie elsewhere.

\section{Attitudes of coaches to injury prevention}

Generally speaking, the attitudes displayed by field hockey coaches suggested they are injury preventionfocused and appreciate the concept of implementing injury prevention methods within their squad. They had a strong awareness of what constituted an injury and felt a responsibility when determining how to handle an athlete who was suffering an injury. All coaches insisted that the health and well-being of the athletes was the key factor in the decision-making process. Interestingly, this is in contrast to coaches in professional sports, where performance was deemed to be the main goal. ${ }^{25}$ Although field hockey coaches displayed generally positive attitudes towards injury and potential injury prevention strategies, limitations in their skills, knowledge and resources restrict their ability to implement them. For example, coaches were not confident when it came to developing and administering specific strengthening programmes, which have been shown to assist in reducing injuries. ${ }^{26-28}$ In Ireland, field hockey, and in fact most sports in general, are amateur in nature. As such, many coaches are employed on a voluntary or semi-professional basis. This perhaps places additional undue pressure on the coach, who cannot be expected to be experts in this field. This did, however, highlight the need for further support staff to be employed within the squads, who are capable of contributing to the safety of athletes while playing. Injury prevention strategies require contributions from multiple levels, including fitness coaches and physiotherapists, ${ }^{29}$ a luxury not available to field hockey athletes in Ireland. Further to their employment within the squad, many coaches had careers away from sport. Despite this, the expectation placed on them is perhaps excessive and unjust. For example, clubs in Ireland compete in European level competitions, often played abroad, requiring some coaches to take leave from work. Indeed, it would be unfair to expect coaches to also carry the burden of injury prevention. Interestingly, however, the prioritisation of athlete safety by field hockey coaches in Ireland is perhaps conflicting with more elite sports, where player welfare is considered important, but not at the expense of performance. ${ }^{12}$ 


\section{Coaches' impact on injury prevention}

While not directly linked to preventing injury in sport, studies have shown that effective communication between coaches and the playing squad, ${ }^{30}$ as well as between the clubs support staff ${ }^{31}$ can indirectly reduce the burden and prevalence of injury. Youth athletes, by definition, are less experienced than their more senior counterparts. Coaches highlighted the need, for this reason, for their communication-style to differ for this cohort. For example, younger athletes tend to play more hockey, but are not experienced when it comes to post-game recovery and other prevention techniques. Therefore, they required more guidance in this respect. This is likely to have placed further burden on coaches. Coaches who apply transformational leadership (ie, a leadership style whereby the leader works with teams to encourage innovation and create change through democratic methods within the squad), tend to oversee fewer injuries across a season. ${ }^{30}$ The field hockey coaches displayed many transformational characteristics. For example, they involved athletes in decision-making regarding managing load during and between games. They also tended to give more autonomy to senior players than their less experienced counterparts, a cohort who tend to suffer the higher rates of injury in sport. ${ }^{32}$ This may be due to younger players having insufficient knowledge or experience. Despite coaches' positive attitudes and some knowledge of injury prevention, specialist support and guidance would provide coaches with additional knowledge to further reduce the risk of injury to athletes. It would also alleviate some of this additional burden that is placed on field hockey coaches in Ireland.

Coaches also felt a particular responsibility for protecting younger players as they felt the domestic calendar is unfavourable to them, as some occasionally play at school, club, regional and international level at the same time. As a result of this, they are often expected to prioritise a number of different teams, with little thought given to the welfare or future development of the player. Mid-season tournaments, such as the all-Ireland school tournament, consist of athletes participating in up to five games over the space of 3 days. This is despite evidence suggesting that rest days are likely to result in athletes being at decreased risk of sustaining injury. ${ }^{33}$ This particularly demanding domestic calendar for younger players appears to be unique to Ireland. For example, as the league standard in Ireland is lower than that of the professional leagues in Europe and Australia, athletes often begin to participate in senior men's leagues from as young as 15 years old. It is seldom in sport that young athletes could be expected to play for up to five different squads in total. This may require intervention at a governing level, restricting the number of matches that school-aged athletes are permitted to play.

\section{Contextual barriers to injury prevention}

Oftentimes in sport, a number of barriers restrict the coaches' ability to prevent injuries, many of which are out of the coaches' control. This occurred at multiple levels, from the athlete up to national governing body. Field hockey athletes in Ireland tend to be communitybased, limiting the contact time that coaches have with athletes. This has a significant impact on the implementation of injury prevention strategies. Many teams train only for $1.5-2$ hours, two times per week. Coaches indicated some reluctance to dedicate some of their time to such strategies, instead of relying on athletes conducting strength and conditioning sessions in their own time. Furthermore, such strategies need to be consistent to be successful. ${ }^{34}$ Athletes' absence from training due to other commitments, as is the norm in amateur sport, is likely to have a significant impact on this. Similar difficulties were highlighted in soccer. ${ }^{35}$

Environmental factors, over which field hockey coaches have little or no control, were considered to be a major contributing factor to injury and are likely to be a barrier when implementing injury prevention strategies. For the typical senior club athlete, fixture congestion remains an important problem. Around European field hockey leagues, a mid-season winter break is held over the winter months. This provides athletes with a period of time to rest and recover, but also to allow for the popular indoor hockey season to commence. In Ireland, the winter break is considerably shorter than those in other major European leagues. According to coaches, the introduction of this winter break caused fixture congestion at the start and end of the indoor hockey season, when the winter break was beginning and ending. Fixture congestion, and the resulting fatigue, increases an athlete's risk of sustaining injury when not managed appropriately. ${ }^{36}$

\section{Moving from linear to non-linear models of injury prevention}

In 1992, van Mechelen et al developed the 'sequence of prevention'. This four-stage guide was the first model of its kind developed to tackle a persistent and growing problem: sporting injuries. However, important factors such as the context in which the sport is played, and the many complexities associated with human behaviour need to be explored if we wish to fully understand the problem. ${ }^{11}$ For example, the amateur nature of field hockey in Ireland caused a number of issues to arise, including many coaches being voluntary or semiprofessional in their roles. This significantly impacted on their time and effort commitments. Furthermore, there are a number of barriers to injury prevention at environmental and societal levels, which may be out of the control of coaches. Until these barriers are addressed, future interventions will likely prove unsuccessful, a discovery that would likely have been missed under the framework of the 'sequence of prevention'. This study provides further evidence of the need to move away from linear frameworks, such as the sequence of prevention and towards more non-linear frameworks that take into account the behaviour of stakeholders and context of the sport. $^{11}$ 


\section{Implications}

Further education of coaches would be of benefit to preventing injuries in athletes, which could be provided for during formal coaching courses. While it is not realistic to expect coaches to fulfil the roles of physiotherapists or sport scientists, they should have a basic understanding of training load and warmups. It may also be of benefit to ensure that coaches hold valid first aid qualifications. The importance of coaching style is highlighted throughout this study. The benefits to athlete welfare in transformational coaching styles should also be described to coaches. Furthermore, a restructure of the domestic calendar may improve the safety and well-being of athletes. This could include an extension of the winter break to prevent any overlap between the field and indoor hockey seasons, as well as the all-Ireland school tournament. Although previous injury prevention warmups have proved successful in other team sports, ${ }^{37} 38$ until such a time that improved education can be provided to both coaches and athletes, it is unlikely that such strategies would be successful, as coaches in this study had the perception that athletes undervalue warmups. Future prevention strategies should be relatively short, without compromising its usefulness, to accommodate the limited exposure time that athletes have with their coaches.

\section{CONCLUSIONS}

In conclusion, field hockey coaches had a positive attitude towards injury prevention and understood the benefits of implementing interventions within the squad. However, they often lacked the skills and knowledge required to fully implement effective prevention programmes. Environmental factors outside of the coaches' control, such as the domestic calendar further impacted on the coaches' ability to prevent injury. In addition, athletes themselves often represented a barrier to such measures through their limited understanding of injury and injury prevention, as well as other commitments such as work and school, highlighting the amateur nature of the sport. However, despite this, coaches tend to prioritise the welfare of players over a win-at-all-costs mentality, emphasising the potential that educating coaches with respect to injury prevention could have on injury rates within a squad.

\section{Twitter Huw Rees@HuwRees2}

Acknowledgements This study was carried out as part of a scholarship from the Institute for Sport and Health in University College Dublin.

Contributors All authors have contributed to the development of this manuscript.

Funding The authors have not declared a specific grant for this research from any funding agency in the public, commercial or not-for-profit sectors.

Competing interests None declared.

Patient and public involvement Patients and/or the public were not involved in the design, or conduct, or reporting, or dissemination plans of this research.

Patient consent for publication Not required.

Ethics approval Ethical approval was granted for this study from the Human Research Ethics Committee, University College Dublin (LS-17-86-Rees-Blake).
Provenance and peer review Not commissioned; externally peer reviewed.

Data availability statement № data are available.

Supplemental material This content has been supplied by the author(s). It has not been vetted by BMJ Publishing Group Limited (BMJ) and may not have been peer-reviewed. Any opinions or recommendations discussed are solely those of the author(s) and are not endorsed by BMJ. BMJ disclaims all liability and responsibility arising from any reliance placed on the content. Where the content includes any translated material, BMJ does not warrant the accuracy and reliability of the translations (including but not limited to local regulations, clinical guidelines, terminology, drug names and drug dosages), and is not responsible for any error and/or omissions arising from translation and adaptation or otherwise.

Open access This is an open access article distributed in accordance with the Creative Commons Attribution Non Commercial (CC BY-NC 4.0) license, which permits others to distribute, remix, adapt, build upon this work non-commercially, and license their derivative works on different terms, provided the original work is properly cited, appropriate credit is given, any changes made indicated, and the use is non-commercial. See: http://creativecommons.org/licenses/by-nc/4.0/.

\section{ORCID iD}

Huw Rees http://orcid.org/0000-0003-2609-4474

\section{REFERENCES}

1 Casamichana D, Morencos E, Romero-Moraleda B, et al. The use of generic and individual speed thresholds for assessing the competitive demands of field hockey. J Sports Sci Med 2018;17:366-71.

2 Delfino Barboza S, Nauta J, van der Pols MJ, et al. Injuries in Dutch elite field hockey players: a prospective cohort study. Scand J Med Sci Sports 2018;28:1708-14.

3 Rees H, Shrier I, McCarthy Persson U, et al. Transient injuries are a problem in field hockey: a prospective one-season cohort study. Trans/ Sports Med 2020;3:119-26.

4 Rees H, McCarthy Persson U, Delahunt E, et al. Epidemiology of injuries in senior men's field hockey: a two-season prospective observational injury surveillance study. J Sports Sci 2020;38:2842-9.

5 Bahr R, Thorborg K, Ekstrand J. Evidence-Based hamstring injury prevention is not adopted by the majority of champions League or Norwegian premier League football teams: the Nordic hamstring survey. Br J Sports Med 2015;49:1466-71.

6 Finch $\mathrm{C}$. A new framework for research leading to sports injury prevention. J Sci Med Sport 2006:9:3-9.

7 Glass TA, McAtee MJ. Behavioral science at the crossroads in public health: extending horizons, envisioning the future. Soc Sci Med 2006;62:1650-71.

8 van Mechelen W, Hlobil H, Kemper HCG. Incidence, severity, aetiology and prevention of sports injuries. Sports Medicine 1992;14:82-99.

9 Bekker S, Clark AM. Bringing complexity to sports injury prevention research: from simplification to explanation. $\mathrm{Br} J$ Sports Med 2016;50:1489-90.

10 Verhagen E, Bolling C. We Dare to ask new questions. Are we also brave enough to change our approaches? Trans/ Sports Med 2018;1:54-5.

11 Bolling C, van Mechelen W, Pasman HR, et al. Context Matters: Revisiting the First Step of the 'Sequence of Prevention' of Sports Injuries. Sports Med 2018;48:2227-34.

12 Bolling C, Barboza SD, van MW. Coaches, and physiotherapists perceive a sports injury. Trans/ Sports Med 2019;2:17-23.

13 Bolling C, Mellette J, Pasman HR, et al. From the safety net to the injury prevention web: applying systems thinking to unravel injury prevention challenges and opportunities in Cirque Du SOLEIL. BMJ Open Sport Exerc Med 2019;5:e000492.

14 Brink MS, Frencken W GP, Jordet G, et al. Coaches' and players' perceptions of training dose: not a perfect match. Int J Sports Physiol Perform 2014;9:497-502.

15 Tong A, Sainsbury P, Craig J. Consolidated criteria for reporting qualitative research (COREQ): a 32-item checklist for interviews and focus groups. Int J Qual Health Care 2007;19:349-57.

16 Poucher ZA, Tamminen KA, Caron JG. Thinking through and designing qualitative research studies: a focused mapping review of 30 years of qualitative research in sport psychology. Int Rev Sport Exerc Psychol 2019:1-24.

17 Goodman LA. Snowball sampling. Ann. Math. Statist. 1961:32:148-70.

18 Braun V, Clarke V, Weate P. Using thematic analysis in sport and exercise research.. Routledge Handb Qual Res Sport Exerc 2016:191-205. 
19 Trainor LR, Crocker PRE, Bundon A, et al. The rebalancing act: Injured varsity women athletes' experiences of global and sport psychological well-being. Psychol Sport Exerc 2020;49:101713.

20 NVivo qualitative data analysis software | QSR international. Available: https://www.qsrinternational.com/nvivo/home

21 Braun V, Clarke V. Using thematic analysis in psychology. Qual Res Psychol 2006;3:77-101.

22 Thematic analysis - The University of Auckland. Available: https:// www.psych.auckland.ac.nz/en/about/thematic-analysis.html\#95c4 b0bee0b9774eee5f7ba22cb91d53 [Accessed 05 Feb 2020].

23 Tracy SJ. Qualitative Quality: Eight "Big-Tent” Criteria for Excellent Qualitative Research. Qual Inq 2010;16:837-51.

24 Denzin NK, Lincoln YS. Introduction: The discipline and practice of qualitative research. In: Strategies of qualitative inquiry. 3rd ed. Sage Publications, Inc, 2008: 1-43.

25 Bolling C, Delfino Barboza S, van Mechelen W, et al. Letting the cat out of the bag: athletes, coaches and physiotherapists share their perspectives on injury prevention in elite sports. Br J Sports Med 2020;54:871-7.

26 Al Attar WSA, Soomro N, Sinclair PJ, et al. Effect of injury prevention programs that include the Nordic hamstring exercise on hamstring injury rates in soccer players: a systematic review and metaanalysis. Sports Med 2017;47:907-16.

$27 \mathrm{Kim} \mathrm{E}$, Choi H, Cha J-H, et al. Effects of neuromuscular training on the Rear-foot angle kinematics in elite women field hockey players with chronic ankle instability. J Sports Sci Med 2017;16:137-46.

$28 \mathrm{Kim} \mathrm{T,} \mathrm{Kim} \mathrm{E,} \mathrm{Choi} \mathrm{H.} \mathrm{Effects} \mathrm{of} \mathrm{a} \mathrm{6-week} \mathrm{neuromuscular}$ rehabilitation program on Ankle-Evertor strength and postural stability in elite women field hockey players with chronic ankle instability. J Sport Rehabil 2017;26:269-80.

29 O'Brien J, Finch CF. Injury prevention exercise programmes in professional youth soccer: understanding the perceptions of programme deliverers. BMJ Open Sport Exerc Med 2016;2:e000075.
30 Ekstrand J, Lundqvist D, Lagerbäck L, et al. Is there a correlation between coaches' leadership styles and injuries in elite football teams? A study of 36 elite teams in 17 countries. Br J Sports Med 2018;52:527-31.

31 Ekstrand J, Lundqvist D, Davison M, et al. Communication quality between the medical team and the head coach/manager is associated with injury burden and player availability in elite football clubs. Br J Sports Med 2019;53:304-8.

32 Pfirrmann D, Herbst M, Ingelfinger P, et al. Analysis of injury incidences in male professional adult and elite youth soccer players: a systematic review. J Athl Train 2016;51:410-24.

33 Orlando C, Levitan EB, Mittleman MA, et al. The effect of rest days on injury rates. Scand J Med Sci Sports 2011;21:e64-71.

34 Owoeye OBA, McKay CD, Verhagen EALM, et al. Advancing adherence research in sport injury prevention. Br J Sports Med 2018;52:1078-9.

35 Gebert A, Gerber M, Pühse U, et al. Injury prevention in amateur soccer: a nation-wide study on implementation and associations with injury incidence. Int J Environ Res Public Health 2019;16:1593.

36 Bengtsson $\mathrm{H}$, Ekstrand J, Hägglund M. Muscle injury rates in professional football increase with fixture congestion: an 11-year follow-up of the UEFA champions League injury study. $\mathrm{Br} J$ Sports Med 2013;47:743-7

37 Soligard T, Myklebust G, Steffen K, et al. Comprehensive warm-up programme to prevent injuries in young female footballers: cluster randomised controlled trial. BMJ 2008;337:a2469.

38 O'Malley E, Murphy JC, McCarthy Persson U, et al. The effects of the Gaelic athletic association 15 training program on neuromuscular outcomes in Gaelic football and Hurling players: a randomized cluster trial. J Strength Cond Res 2017;31:2119-30. 